\title{
Apexification with Calcium Hydroxide: 27 Months Follow Up of a Case
}

\author{
Chowdhury AFMA ${ }^{1}$, Alam A$^{2}$, Sarkar $\mathrm{UK}^{3}$, Mahmud AA ${ }^{4}$, Habiba U ${ }^{5}$, Rabby MAI ${ }^{6}$
}

\begin{abstract}
Dental trauma is common in young patients with immature teeth. When necrosis of pulp follows in such a tooth, apexification of the root is the most recognized and accepted treatment of choice. Calcium hydroxide paste is the most popular material used to induce the apical hard tissue barrier which may be composed of different tissues. Hertwig's epithelial root sheath and (or) its remnants, the cell rests of Malassez may contribute to the apical closure. In the presented case, careful multidisciplinary treatment approach helped to regain esthetic and function. After 27 months the tooth showed every sign of success.
\end{abstract}

Key words: Apexification, Calcium hydroxide, Hertwig's epithelial root sheath, Epithelial cell rests of Malassez.

\section{Introduction}

Dental trauma happens most frequently in young patients, who generally present with immature teeth ${ }^{1}$. When such teeth with open apex suffer pulp pathology, root formation stops. Consequently, wide canals with thin and fragile walls and open or even 'blunderbuss' apex make chemomechanical debridement difficult and hamper apical closure $^{2}$. In these conditions, induction of root formation(apexogenesis) or root end closure(apexification) are the accepted treatment options.

Selection of teeth for apexogenesis or apexification depends on clinical and radiographic features. If the patient reports within 24 hours of traumatic pulp exposure, apexogenesis is the treatment of choice. On the contrary, if the patient fails to report within 24 hours of pulp exposure or there are

1. Corresponding Author: Dr A.F.M. Almas Chowdhury BDS, DDS
FCPS (Part-II) Trainee
Conservative Dentistry \&Endodontics
Dhaka Dental College \& Hospital
E-mail:shovon_715@ yahoo.com
2. Dr. Arefin Alam BDS
Lecturer, Conservative Dentistry \&Endodontics
Sapporo Dental College \& Hospital
3. Dr. Uttam Kumar Sarkar
Medical Officer, Conservative Dentistry \& Endodontics
Sapporo Dental College \& Hospital
4. Dr. Abdullah Al Mahmud BDS
FCPS (Part-II) Trainee
Conservative Dentistry \&Endodontics
Dhaka Dental College \& Hospital
5. Dr. Umma Habiba BDS, DDS, MCPS
Assistant Professor
Oral Pathology and Periodontology
Sapporo Dental College\& Hospital
6. Dr. Md. Atiqul Islam Rabby BDS
Dental Surgeon
Pacific Dental Care, Farmgate, Dhaka

definite signs of pulp non-vitality, apexification is the only conservative treatment option left.

Apexificationrequires the chemomechanical debridement of the canal followed by placement of an intracanal medicament to assist or stimulate apical healing and formation of a horizontal apical barrier ${ }^{3}$ at the apical end of the root canal to facilitate the subsequent obturation of the canal without voids and excess material in the periapical tissue $^{4}$. The most common material used in apexification is calcium hydroxide 5 .

The apical barrier varies in composition. Most often a cementum-like tissue is recognized. Other times the tissue is so irregular that all that can be said about it is that it is a mineralized tissue which often contains inclusions of soft tissue $^{4}$. Dentine and bone can also form ${ }^{6}$, but most common result is a combination of dentine, cementum and bone ${ }^{7,8}$, with connective tissue and calcium hydroxide occasionally mixed in with them ${ }^{9}$. Therefore, such an apical hard tissue bridge does not seal the root canal. It only renders a barrier against which a bacteria-tight seal of the canal may be achieved by means of the root filling materials ${ }^{4}$.

Hertwig's epithelial root sheath is significant in the development of the apical barrier ${ }^{10}$. It can survive periapical inflammation and continue root development when the inflammatory process is eliminated ${ }^{11}$. By stimulating epithelial root sheath cells calcium hydroxide assists in apical closure.

\section{Case report}

A 12-year old boy with a non-contributory medical history was referred to theDepartment of Conservative Dentistry andEndodontics, Dhaka Dental College and Hospital for the management of a discolored maxillary left central incisor (tooth 21). The tooth had become non-vital and infected following an injury resulted from an accidental blow two years back.Discoloration, horizontal crown fracture and mild pain to percussion were the positive clinical findings (fig.1-A).Radiographic examination revealed a relatively short root with open apex associated with periapical radiolucency about $3 \mathrm{~mm}$ in diameter (fig.1-B). The shortness of the root was assumed to be due to hamper in the root formation resulting from apical inflammation.

The patient was explained that initially a conservative orthograde endodontic approach will be undertaken with the aim of achieving microbiological control, periapical healing and apical closure. Should such an approach fail, the patient was informed that periapical surgery might be necessary. 
At this initial appointment, access to the canal was established and a thin non-purulent discharge from the canal was noticed. Cotton roles and saliva ejector were used for isolation. The canal was then gently irrigated with normal saline. A cotton pellet was placed within the pulp chamber, the cavity kept open and the patient was discharged with the advice of warm saline gurgling frequently over the next 48 hours. A 3rd generation cephalosporin (Cefixime $400 \mathrm{mg}$, 12 hourly for 7 days) was also prescribed to aid in periradicular microbiological control.

On the next visit,working length was determined $19 \mathrm{~mm}$, $2 \mathrm{~mm}$ short from the radiographic apex. The canal was then instrumented to an apical size of 110 with Hedström files and irrigated with $1.0 \%$ sodium hypochlorite and normal saline solution alternately. After drying with paper point the canal was medicated with pure calcium hydroxide (Calcium Hydroxide ) and the access cavity sealed with Zinc oxide (Caviton).

After one week, the symptoms had subsided and the patient presented with a comfortable tooth. After thorough irrigation and cleaning, radio-opaque calcium hydroxidepaste (Calform- $\mathrm{RC}^{€}$ ) was packedinto the canal with good contact to the periapical tissue (fig.1-C) and the access sealed.

On the next visit after one month a periapical radiograph showed that the canal was still packed with calcium hydroxide with slight dissolution of paste in the apical 1$1.5 \mathrm{~mm}$ (fig.1-D). So, the patient was appointed again after 2 months.
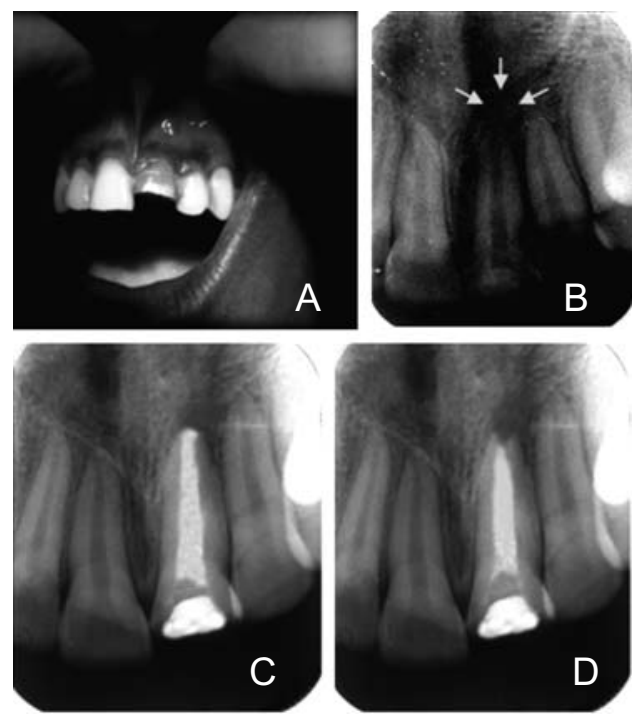

Fig 1:A. Preoperative image showing disclosure and fractured 21.

B. Preoperative radiograph showing open apex with periapical radiolucency in 21 .

C. Calcium hydroxide paste packed with good contact to periapical tissue.

D. Dissolution of paste in the apical 1-1.5 mm.

Three months after the paste application, at the 5 th visit, the patient presented no symptoms and a new periapical view showed dissolution of the calcium hydroxidefrom the apical 3-4 $\mathrm{mm}$ of the canal with no sign of apical closure. The tooth was re-entered and a number 110 paper point was gently introduced within the canal to check clinically whether calcified barrier had been formed or not. As no barrier was formed, fresh calcium hydroxide paste was packed within the canal, the cavity sealed, the patient discharged and was advised to visit the hospital again after 3 months.

But unfortunately the patient visited after long 5 months. A follow-up periapical view was then taken and the patient was clinically examined. This time a faint sensation of resistance was felt with paper point and the radiograph also confirmed the presence of a horizontal bridge. But as the patient missed the scheduled visit and there was a slight discomfort to percussion again calcium hydroxide pastewas applied, the cavity sealed and the patient appointed after 3 months.

After 4 months, again missing the scheduled visit, the patient came to the hospital. This time examination with paper point and periapical radiographconfirmed the formation of an apical bridge (fig.2-A). The canal was then prepared to an apical size of $120 \mathrm{~K}$ file, obturated with guttapercha cone and restored with Caviton (fig.2-B).

After 1 week, a follow-up clinical examination of the 21 was done to see if there was any post-obturation complication. As there was no complain, the patient was asked to visit after 3 months for crowning.

As the clinical and radiographic review of the tooth 3 months later was satisfactory, post-core build-up was done on 21 using a suitable size preformed post $\left(\right.$ Dental $\left.^{\Phi}\right)$ with light cure composite resin restorative material (Solare ${ }^{\mathfrak{x}}$ ) and finally a porcelain fused to metal crown was placed on the tooth (fig.2-C).

A review of the tooth was carried out 12 months (27 months after first visit) later which showed no abnormality in the periapical tissues (fig.2-D).

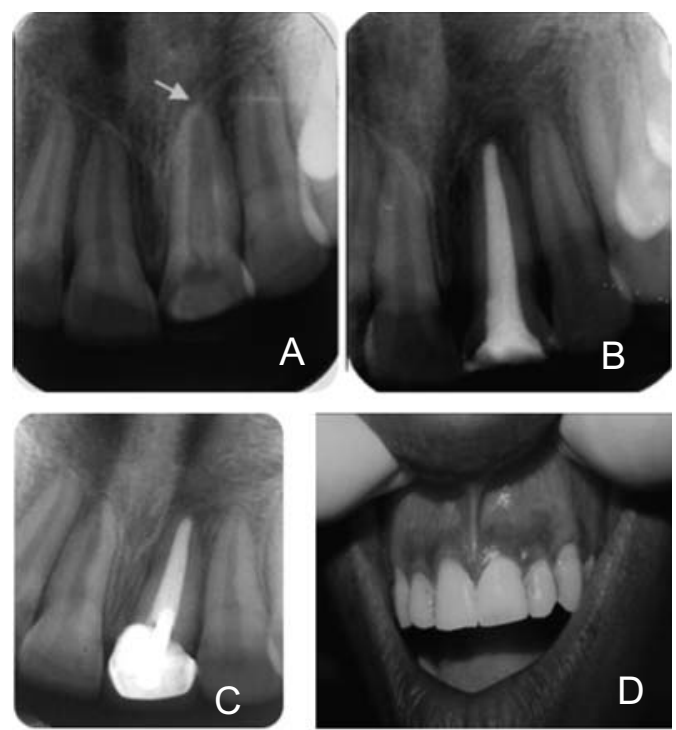

Fig. 2: A. Apical Bridge formation in 21.

B. Obturation with gutta percha cone.

C. Post-core with crown

D. Post-operative image after crown insertion. 
Calcium Hydroxide, Deepti Dental Products, Ratnagiri, India.

Caviton, GC Corporation, Tokyo, Japan.

$€$ Calform, Ammdent, Mohali, India.

đ Dental, Nordin, Chailly, Switzerland.

$æ$ Solare, GC Corporation, Tokyo, Japan.

\section{Discussion}

This case resulted in successful apexification despite of a prolonged history of trauma and irregular visits of the patient.Since the root formation was incomplete during the trauma, the Hertwig's epithelial root sheathand (or) its remnants, the cell rests of Malassez may have contributed to the apical closure. Although these cells decrease in number with age ${ }^{12}$, they retain the ability to undergo cell division $^{13}$. So, as long as there is a periodontal ligament present anywhere on the root, the formation of a hard tissue barrier is a reality.

The ability of calcium hydroxide to induce a hard tissue barrier by stimulating cellular activity in epithelial root sheath is accepted and its osteogenic potential is known for some time ${ }^{14}$. It also accelerates the natural healing functions in the periapical tissues ${ }^{15}$. The favourable consequences of its using can be attributed to its anti-inflammatory, acid neutralizing, alkaline phosphatase activating and antibacterial action ${ }^{16}$. It is also less toxic, bactericidal, biocompatible and has tissue dissolving property ${ }^{17,18}$.

Calcium hydroxide should be refreshed every three months, which requires multiple visits with inevitable clinical costs and the increased risk of tooth fracture since many dressing changes are necessary till the formation of a calcified barrier ${ }^{19,20}$. In this case when new, clean calcium hydroxide paste had been introduced into the canal, it was changed in every three months. However, in very young patients with 'blunderbuss' apex, the paste may dissolve and wash out from the root canal so quickly that, at least at the beginning of the treatment, it may have to be changed more often than every three months. Granulation tissue which often grows into the apical area of a wide open root canal is sometimes difficult to remove with instruments. However, like in the presented case it necrotizes when calcium hydroxide is packed into the canal, and at the subsequent visit can be rinsed out of the canal with sodium hypochlorite ${ }^{4}$.

The time required for apical barrier formation may be as long as twenty months using calcium hydroxide. Age and presence of symptoms or periradicular radiolucencies may affect the time needed to form an apical barrier ${ }^{21}$. In this case apical closure was achieved in around twelve months. Due to the long term nature of the apexification procedure, periapical healing is usually a fact long before the immature tooth is ready to be obturated. However, the formation of an apical hard tissue barrier in itself is no criterion for periapical healing. Non-vital immature teeth are often traumatized and remain undiagnosed. Though in such cases apical periodontal communications may allow ingress of bacteria from oral cavity to sustain a periapical inflammation, apical barriers may form without periapical healing ${ }^{4}$.
The frequency of periapical healing and apical hard tissue closure of non-vital immature teeth after long-term calcium hydroxide treatment is in the range of $90-95 \%$, which shows that the treatment has predictable outcome. On the other hand, if an apexification procedure is not performed prior to obturating the root canal of immature tooth, the success rate of the treatment is less than $50 \%{ }^{4}$.

The majority of dental trauma patients require multidisciplinary cooperation.Adequate integrated treatment planning, coordination, and execution are necessary for the proper management of complex cases ${ }^{22,23,24}$. In the presented case, the patient regained his esthetic and function due to cooperation of Endodontics, Operative Dentistry, Periodontology and Prosthodontics departments.

In the presented case calcium hydroxide has proven its ability in apical healing and stop formation by stimulation of Hertwig's epithelial root sheath and(or) its remnants, the cell rests of Malassez. The extruded material was also well accepted by the periradicular tissue. Since a considerable period of time and many dressing changes are necessary till the formation of a calcified barrier, search for promising alternative medicaments are encouraged. A multidisciplinary planning and treatment approach is significant for favourable prognosis of such cases.

\section{References}

1. Navabazam A, Farahani SS. Prevalence of traumatic injuries to maxillary permanent teeth in 9 to 14-years old school children in Yazd, Iran. Dent Traumatol. 2010;26:154-77.

2. GaliPradeep, Soumya Natesan, DeivanayagamKandaswamy: "The complete endodontic obturation of immature permanent central incisors with mineral trioxide aggregate and using obturated MTA as barrier for walking bleaching" J Cons Dent: 2007:10:93-98.

3. Peter Parashos, MDSc (Melb), FRACDS. Apexification: Case report. Austalian Dental Journal 1997;42:43-6.

4. Leif Tronstrad (2007) Clinical Endodontics: A Textbook, 2nd revised edition edn., NY: Thieme.

5. Cvek M. Endodontic management of traumatized teeth. In: Andreasen JO, Andreasen FM, Eds. Textbook and colour atlas of traumatic injuries to the teeth. 3rd edn. Copenhagen: Munksgaard, 1994:543.

6. Torneck CD, Smith J. Biologic effects of endodontic procedures on developing incisor teeth. I. Effect of partial and total pulp removal. Oral Surg Oral Med Oral Pathol 1970;30:258-66.

7. Dylewski JJ. Apical closure of non-vital teeth. Oral Surg Oral Med Oral Pathol 1971;32:82-9.

8. Torneck CD, Smith JS, Grindell P. Biologic effects of endodontic procedures on developing incisor teeth. IV. Effect of debridement procedures and calcium hydroxide - camphorated parachlorophenol paste in the treatment of experimentally induced pulp and periapical disease. Oral Surg Oral Med Oral Pathol 1973;35:541-54. 
9. Yang S-F, Yang Z-P, Chang K-W. Continuing root formation following apexification treatment. Endod Dent Traumatol 1990;6:232-5.

10. Feiglin B. Differences in apex formation during apexification with calcium hydroxide paste. Endod Dent Traumatol 1985;1:195-9.

11. Heithersay GS. Stimulation of root formation in incompletely developed pulpless teeth. Oral Surg Oral Med Oral Pathol 1970;29:620-30.

12. Melcher AH, McCulloch CAH. Periodontal ligament. In: Bhaskar SN, ed. Orban's oral histology and embryology. 11th edn. St. Louis: Mosby, 1991.

13. Trowbridge HO, Shibata F. Mitotic activity in epithelial rests of Malassez. Periodontics 1967;50:109.

14. Mitchell DF, Shankwalker GB. Osteogenic potential of calcium hydroxide and other materials in soft tissue and bone wounds. JDent Res 1958;37:1157-63.

15. Matsumiya S, Kitamura M. Histo-pathological and histo-bacteriological studies of the relation between the condition of sterilization of the interior of the root canal and the healing process of periapical tissues in experimentally infected root canal treatment. Bull TokyoDentColl 1960;1:1-19.

16. Sauza V, BernablePFE,Holland R, Navy MJ, Mellow W, Otobonl "Treatment naocururgico de dentis com lesisperiapicasis” Rev Brasil Odontol:1989; 49;39-46.

17. Bystrom A, Claeson R, Sundqvist G. " Antibacterial effect of camphorated paramonochlorophenol, camphorated phenol and calcium hydroxide in the treatment of infected root canals" Endod Dent Traumatol 1985:1:170-175.

18. Sjogren U, Figdor D, Sp ngberg L, Sundqvist G. The antimicrobial effect of calcium hydroxide as a shortterm intracanal dressing. IntEndod J 1991;24:119-125.

19. Andreasen JO, Farik B, Munksgaard EC. Longtermcalciumhydroxide as a root canal dressing may increase the risk of root fracture. Dent Traumatol. 2002;18:134-7.

20. Rafter M. Apexification: a review. Dent Traumatol. 2005;21:1-8.

21. Huang GT. Apexification: the beginning of its end. IntEndod J. 2009;42:855-66.

22. Ertugrul F, Eden E, Ilgenli T. Multidiciplinary treatment of complicated subgingivally fractured permanent central incisors: two case reports. Dent Traumatol. 2008;24:61-6.

23. Leroy RL, Aps JK, Raes FM, Martens LC, De Boever JA. A multidisciplinary treatment approach to a complicated maxillary dental trauma: a case report. Endod Dent Traumatol. 2000;16:138-42.

24. Bindo TZ, de Morais EC, de Campos EA, Gonzaga CC, Correr GM, Baratto-Filho F. Multidisciplinary approach of a crown-root fracture using intentional replantation: a case report. Pediatr Dent. 2010;32:428-32. 